\title{
Evaluation of bilirubin as possible protective factor in the prevention of retinopathy of prematurity
}

\author{
Dan D Gaton, Joseph Gold, Ruth Axer-Siegel, Eliahu Wielunsky, Nora Naor, Ilana Nissenkorn
}

\begin{abstract}
Retinopathy of prematurity (ROP) appears to be a multifactorial disease, the prevention of which is probably impossible even with the most accurate methods of blood-gas monitoring and oxygen restrictions. The oxidative processes and consequent formation of free radicals are probably influenced by the availability of various antioxidants in the immature retina. Bilirubin, the end product of haem catabolism, has recently been regarded as a potential physiological antioxidant. In order to test the suggestion as to the possible effect of bilirubin in reducing the incidence of ROP a retrospective study was undertaken of the medical records of 151 neonates born between 1984 to 1988 who weighed less than $1500 \mathrm{~g}$. Of these, 78 had various degrees of ROP, whereas 73 had no ROP and served as a control group. The daily mean bilirubin values were analysed in accordance with gestational age and birth weight as well as the severity of ROP, and the results were compared with those obtained for the control group. The results showed no correlation between bilirubin levels and severity of ROP in all subgroups of gestational age and birth weight. These findings indicate that there is no apparent protective effect of bilirubin on the development of ROP.
\end{abstract}

During the past few decades there have been dramatic advances in the care of critically ill newborn babies, resulting in the greatly improved survival of infants with extremely low birth weights. Phelps ${ }^{1}$ estimated that $30-35 \%$ of infants with a birth weight of $1000 \mathrm{~g}$ or less will develop cicatricial retinopathy of prematurity, with $8 \%$ becoming blind. As ROP appears to be a multifactorial disease, ${ }^{2-8}$ its complete prevention, even by the most accurate methods of monitoring blood gases and oxygen restriction, has been assumed to be impossible. However, the search for possible influencing factors continues.

Current data indicate that oxidative processes in the tissues may be of vital importance in the initiation of the disease. ${ }^{3+}$ These oxidative pro-

Table I Infant groups according to ROP stage and gestation age

\begin{tabular}{lccccc}
\hline $\begin{array}{l}\text { Gestational } \\
\text { age (wks) }\end{array}$ & 0 & \multicolumn{5}{c}{ Stage of ROP } & \multicolumn{1}{c}{ R } & 2 & 3 & Total \\
\hline$\leqslant 27$ & 7 & 5 & 12 & 16 & 40 \\
$\leqslant 28$ & 8 & 6 & 18 & 23 & 55 \\
$\leqslant 29$ & 17 & 11 & 23 & 25 & 76 \\
$\leqslant 30$ & 28 & 14 & 26 & 28 & 96 \\
$\leqslant 31$ & 43 & 17 & 27 & 28 & 115 \\
$\leqslant 32$ & 52 & 19 & 28 & 29 & 128 \\
$\leqslant 33$ & 64 & 19 & 28 & 29 & 140 \\
$\leqslant 34$ & 73 & 20 & 29 & 29 & 151 \\
\hline
\end{tabular}

cesses and the consequent formation of free radicals are probably influenced by the availability of various antioxidants in the immature retina. ${ }^{2-8}$ Stocker et $a l^{9-11}$ have shown that bilirubin is a potential physiological antioxidant. The preliminary data collected by Heyman et $a l^{12}$ suggested that bilirubin may play a protective role in the prevention of ROP. We report here the findings of a retrospective study carried out to evaluate the possible correlation between bilirubin levels and severity of ROP as related to gestational age and birth weight in a group of neonates weighing less than $1500 \mathrm{~g}$.

\section{Patients and methods}

We reviewed the medical records of all neonates with a gestational age of 34 weeks or less and weighing less than $1500 \mathrm{~g}$ who were admitted to the neonatal intensive care unit from January 1984 to December 1988: 151 premature infants met these criteria. ROP was found in 78 , whereas 73 had no ROP and served as controls.

The 78 infants with ROP were grouped according to the severity of ROP on the basis of the International Classification of ROP.13 Twenty had stage 1 disease, 29 had stage 2 , and 29 had stage 3 ROP. None of the babies had stages 4 or 5 . To test the possible correlation between bilirubin levels and ROP in neonates with different gestational age and birth weight we divided the patients into several subgroups. Table 1 gives the eight gestational age subgroups and Table 2 the four birth weight subgroups.

The mean daily bilirubin levels in the first 14 days of life were calculated. These values were plotted in the different ROP, gestational, age and birth weight subgroups. The data were analysed statistically by Student's $t$ test.

\section{Results}

The mean bilirubin level of the first 14 days was $5.95 \mathrm{mg} / \mathrm{dl}(102 \mu \mathrm{mol} / \mathrm{l})$ in babies with ROP as compared with $6.05 \mathrm{mg} / \mathrm{dl}(103 \mu \mathrm{mol} / \mathrm{l})$ in neonates without retinopathy; this difference has no statistical significance ( $p>0.05)$.

The daily mean bilirubin values were very similar in infants with ROP as compared with those without ROP ( $p>0.05)$ (Fig 1). Further-

Table 2 Infant groups according to ROP stage and birth weight

\begin{tabular}{lccccc}
\hline $\begin{array}{l}\text { Birth weight } \\
(\mathrm{g})\end{array}$ & 0 & \multicolumn{4}{c}{ Stage of ROP } \\
\hline$<750$ & - & 1 & 2 & 3 & Total \\
\hline$<1000$ & 4 & 6 & 15 & 2 & 3 \\
$<1250$ & 33 & 11 & 25 & 27 & 43 \\
$<1500$ & 73 & 20 & 29 & 29 & 151 \\
\hline
\end{tabular}




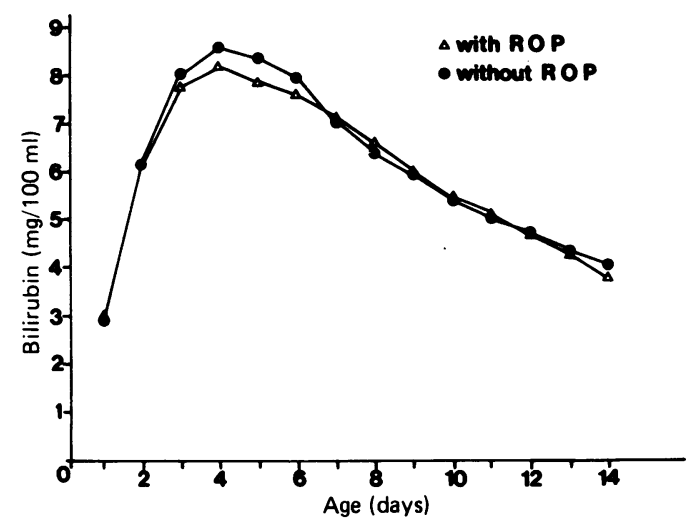

Figure 1 Presence or absence of $R O P$ in relation to bilirubin levels. SI conversion: $\mathrm{mg} / 100 \mathrm{ml} \times 17 \cdot 1=\mu \mathrm{mol} / \mathrm{l}$.

more, comparison of the bilirubin levels in the various ROP stage groups revealed no statistically significant difference between patients with no ROP and patients with ROP stages 1,2 , and 3 $(p>0.05)$ (Fig 2). In the gestational age subgroups of less than 27 to 34 weeks mean bilirubin levels ranged between 5.99 and $6.27 \mathrm{~g} / \mathrm{dl}(102$ and $107 \mu \mathrm{mol} / \mathrm{l}$ ) in the various ROP stages. In the birth weight subgroups of less than 750 to $1500 \mathrm{~g}$ the mean bilirubin levels ranged between 4.83 and $5.99 \mathrm{mg} / \mathrm{dl}(83$ and $102 \mu \mathrm{mol} / \mathrm{l})$. These data shows no statistically significant difference between the various gestational age and birth weight subgroups ( $\mathrm{p}>0.05)$.

Fig 3 serves as an example of this trend in gestational age subgroup of 27 weeks and less, and Fig 4 is an example of the mean daily bilirubin levels in the birth weight subgroup of less than $1250 \mathrm{~g}$.

These results show that the bilirubin level pattern was very similar in all groups of gestational age and birth weight.

\section{Discussion}

It has recently been suggested that endothelial cell damage in the retina is caused by oxygenderived free radicals, which are probably more harmful in premature infants owing to lower levels of antioxidants in the immature retina. ${ }^{34}$

In a post-mortem study of the vitreous humour of premature babies with respiratory distress syndrome Saugstad and Tognum ${ }^{14}$ found high levels of hypoxanthine. This was believed to be not only a sign of hypoxia but also a potential generator of oxygen radicals. Bilirubin, the end product of haem catabolism in

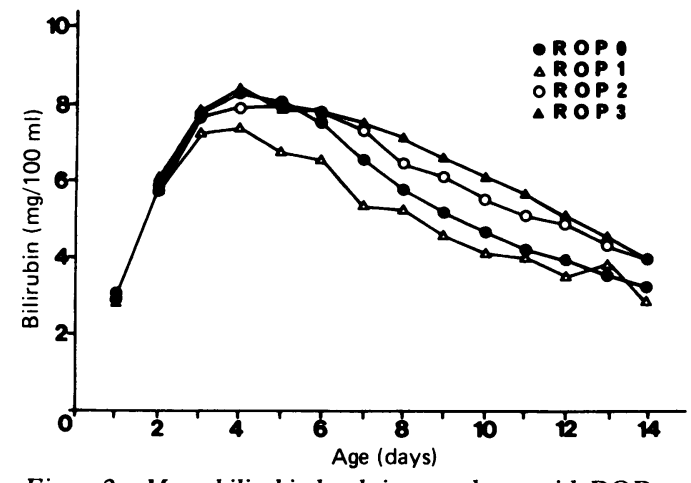

Figure 2 Mean bilirubin levels in accordance with $R O P$ stage. $S I$ conversion: $\mathrm{mg} / 100 \mathrm{ml} \times 17 \cdot 1=\mu \mathrm{mol} / \mathrm{l}$.

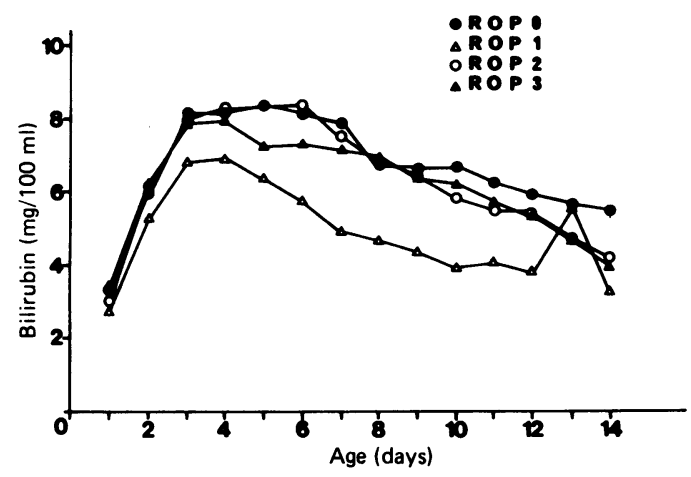

Figure 3 Bilirubin levels in accordance with ROP stage in prematures born $\leqslant 27$ weeks of gestation. SI conversion: $m g /$ $100 \mathrm{ml} \times 17 \cdot 1=\mu \mathrm{mol} / \mathrm{l}$.

mammals, is generally regarded as a potentially cytotoxic lipid-soluble waste product that needs to be excreted. However, the data presented by Stocker et $a l^{9-11}$ support the concept of a beneficial role of bilirubin as a physiological, chainbreaking antioxidant.

Heyman et $a l^{12}$ subsequently raised the question whether bilirubin might have a protective effect in the prevention of ROP. They found that in neonates with ROP (stages 2,3 , or 4) bilirubin levels from day 4 were considerably lower than those in neonates with stage $1 \mathrm{ROP}$ or no ROP, and suggested that bilirubin may have a protective effect in the prevention of ROP.

Our retrospective study of premature neonates, weighing less than $1500 \mathrm{~g}$ and with gestational age of 34 weeks or less, shows a very similar pattern of mean bilirubin levels during the first 14 days of life among infants with stages 1,2 , and 3 ROP as well as infants with no ROP. There were no statistically significant differences in bilirubin levels when considered in relation to severity of ROP, gestational age, or birth weight. These results therefore do not support the concept that bilirubin is a possible protective factor in the prevention of ROP. Furthermore, we assume that bilirubin levels in the first days of life in premature babies are probably not correlated with the development of ROP.

As the main pathological effect of ROP is ischaemia of peripheral retinal areas due to impaired blood supply, it is reasonable to assume that bilirubin levels in the affected regions are low. It is therefore possible that these low

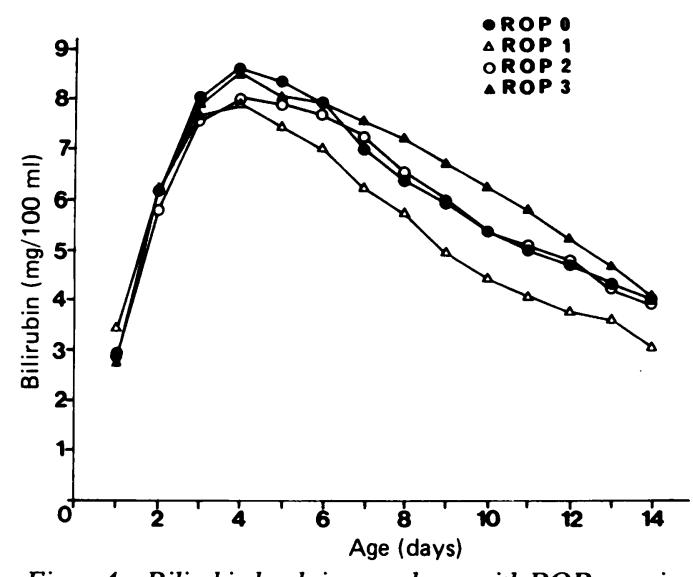

Figure 4 Bilirubin levels in accordance with ROP stage in prematures with birth weight $<1250 \mathrm{~g}$. SI conversion: $m g / 100$ $m l \times 17 \cdot 1=\mu \mathrm{mol} / l$. 
bilirubin levels may be insufficient for the antioxidative potential effect of bilirubin.

Another explanation of the undetected antioxidative effect of bilirubin may be due to the fact that this report reviewed bilirubin levels in the first 14 days of life, a period in which bilirubin is known to be physiologically high. As ROP tends to not appear before 6 weeks of age, it is possible that the time interval between the decrease to normal bilirubin levels and the appearance of ROP is long enough to diminish its protective effect in preventing the disease.

This study was presented in partial fulfilment of the requirements of Tel Aviv University Sackler Faculty of Medicine for the MD degree of Joseph Gold.

1 Phelps DL. Vision loss due to retinopathy of prematurity. Lancet 1981; i: 606.

2 Lucey JL, Dangman B. A re-examination of the role of oxygen in retrolental fibroplasia. Pediatrics 1984; 73: 82-96.

3 Silverman WA, Flynn JT, eds. Retinopathy of prematurity. Contemporary issues in fetal and neonatal medicine. Boston: Blackwell, 1985: 121-52.
4 Ben-Sira I, Nissenkorn I, Kremer I. Retinopathy of prematurity. Surv Ophthalmol 1988; 33: 1-16.

5 Bossi E, Koenher F, Flury B, Zulali FM. Retinopathy of prematurity: a risk factor analysis with univariate and
multivariate statistics. Helv Paediatr Acta 1984; 33: 307-17.

6 Gunn TR, Easdown J, Duterbridge EW, Aranda VJ. Risk factors in retrolental fibroplasia. Pediatrics 1980; 65: 1096-

7 Kretzer FL, Mehta RS, Johnson AT, et al. Vitamin E protects against retinopathy of prematurity through action on spindle cells. Nature 1984; 309: 793-5.

8 Shohat M, Reisner SH, Krikler R, et al. Retinopathy of prematurity: incidence and risk factors. Pediatrics 1983; 72: $159-63$.

9 Stocker R, Yamamoto Y, McDonagh AF, et al. Bilirubin is an antioxidant of possible physiological importance. Science 1987; 235: 1043-6.

10 Stocker R, Ames BN. Potential role of conjugated bilirubin and copper in the metabolism of lipid peroxides in bile. Proc Natl Acad Sci USA 1987; 84: 8130-4.

11 Stocker R, Glazer AN, Ames BN. Antioxidant activity of albumin-bound bilirubin. Proc Natl Acad SciUSA 1987; 84: 5918-22.

12 Heyman E, Ohlsson A, Girschek P. Retinopathy of prematurity and bilirubin. N Englf Med 1989; 320: 256

3 Committee for the classification of retinopathy of prematurity. An international classification of retinopathy of prematurity. Arch Ophthalmol 1984; 102: 1130-5.

14 Saugstadt OD, Tognum TO. High postmortem levels of hypoxanthine in the vitreous humor of premature babies with respiratory distress syndrome. Pediatrics 1988; 81: 395-8. 